\title{
Spondylometaphyseal dysplasia-cone-rod dystrophy syndrome
}

INSERM

\section{Source}

INSERM. (1999). Orphanet: an online rare disease and orphan drug data base. Spondylometaphyseal dysplasia-cone-rod dystrophy syndrome. ORPHA:85167

Spondylometaphyseal dysplasia-cone-rod dystrophy syndrome is characterised by the association of spondylometaphyseal dysplasia (marked by platyspondyly, shortening of the tubular bones and progressive metaphyseal irregularity and cupping), with postnatal growth retardation and prog ressive visual impairment due to cone-rod dystrophy. So far, it has been described in eight individuals. Transmission appears to be autosomal recessive. 